\title{
ANALISIS KUALITAS AIR PADA LOKASI BUDIDAYA IKAN AIR TAWAR DI KECAMATAN SUWAWA TENGAH
}

\author{
Yuniarti Koniyo \\ Program Studi Budidaya Perairan, Universitas Negeri Gorontalo \\ Email: yuniarti.koniyo@ung.ac.id
}

\begin{abstract}
ABSTRAK
Tujuan penelitian untuk mengetahui kualitas air pada lokasi budidaya ikan air tawar di Kecamatan Suwawa Tengah. Manfaat penelitian adalah tersedianya data kualitas air yakni parameter fisik dan kimia air pada lokasi budidaya ikan air tawar di Kecamatan Suwawa Tengah. Metode penelitian adalah observasi, pengukuran langsung di lapangan (in situ) dan laboratorium. Hasil pengukuran parameter kualitas air di lokasi budidaya ikan air tawar Kecamatan Suwawa Tengah yakni Desa Tapadaa, Desa Lompotoo, Desa Duano dan aliran Sungai Bone masih layak untuk kehidupan ikan air tawar dan konsentrasi logam berat $\mathrm{Hg}, \mathrm{Cd}$ dan $\mathrm{Pb}$ masih dibawah ambang batas aman untuk kegiatan budidaya. Nilai parameter fisik dan kimia air hasil pengukuran adalah suhu $30^{\circ} \mathrm{C}-32.4^{\circ} \mathrm{C}$, pH Derajat keasaman 8.1 - 8.5, Oksigen terlarut (DO) $6-10 \mathrm{Mg} / \mathrm{L}$, tingkat kecerahan air $30-40 \mathrm{~cm}$, dan intensitas cahaya 90\%. Hasil pengukuran logam berat yakni merkuri (Hg) 0.00076 ppm - 0.0056, Kadmium (Cd) $0.00003 \mathrm{ppm}-0.00039 \mathrm{ppm}$ sedangkan Timbal $(\mathrm{Pb}) 0.021 \mathrm{ppm}-0.092 \mathrm{ppm}$.
\end{abstract}

Kata kunci: Kualitas Air, Ikan Air Tawar, Suwawa Tengah

\section{ABSTRACT}

The aim of this study was to determine water quality at freshwater fish farming in Central Suwawa District. The benefit of this research is the availability of water quality data that is the physical and chemical parameters of water in the location of freshwater fish farming in Central Suwawa District. The results of the measurement of water quality parameters at the freshwater fish culture location in Suwawa Tengah District namely Tapadaa Village, Lompotoo Village, Duano Village and Bone River flow are still suitable for freshwater fish life and the concentrations of heavy metals $\mathrm{Hg}, \mathrm{Cd}$ and $\mathrm{Pb}$ are still below the safe threshold for activities cultivation. The physical and chemical parameters of the measured water are temperature $30^{\circ} \mathrm{C}-32.4^{0} \mathrm{C}, \mathrm{pH}$ acidity 8.1 - 8.5, dissolved oxygen (DO) 6-10 mg /l, water brightness level 30-40 cm, and light intensity $90 \%$. The measurement results of heavy metals namely mercury $(\mathrm{Hg}) 0.00076 \mathrm{ppm}-0.0056$, Cadmium (Cd) 0.00003 ppm 0.00039 ppm while Lead (Pb) 0.021 ppm - 0.092 ppm.

\section{Keywords: Water Quality, Freshwater Fish, Central Suwawa}

\section{PENDAHULUAN}

Sektor perikanan di Kabupaten Bone Bolango menyediakan sekitar 3575 lapangan kerja bagi rumah tangga pelaku perikanan atau menjadi tumpuan penghidupan bagi kurang lebih 10.625 masyarakat. Pelaku perikanan yang bekerja di sektor perikanan terdiri dari nelayan 1676 orang, pembudidaya ikan 790 orang, unit pengolahan ikan 57 unit, pedagang ikan 195 orang, tenaga kerja di kapal-kapal perikanan 750 orang, dan tenaga kerja yang bekerja di unit pengolahan ikan 110 orang (Dinas Kelautan dan Perikanan Kabupaten Bone Bolango).

Kabupaten Bone Bolango khususnya Kecamatan Suwawa Tengah menetapkan sektor perikanan sebagai salah satu sektor unggulan ekonomi. Dengan strategi pembangunan 'desa tumbuh daerah maju' atau dengan kata lain pembangunan yang bertumpu pada pembangunan ekonomi kerakyatan yang dimulai dari desa-desa nelayan dan desa-desa budidaya, pembangunan perikanan Bone Bolango membutuhkan akselerasi dari segi sumberdaya manusia, baik pelaku perikanan maupun aparat pengelola pembangunan perikanan.

Budidaya ikan air tawar saat ini semakin maju ditunjang meningkatnya sarana prasarana memadai berupa peralatan perikanan, makanan obat-obatan, teknik budidaya yang disempurnakan maupun pemasaran yang lebih baik. Ruang lingkup kegiatan budidaya mencakup pengendalian pertumbuhan dan mortilitas (Tjarmana, 1999).

Pertumbuhan jenis ikan adalah pertambahan ukuran berat atau panjang pada suatu waktu tertentu. Sedangkan pertumbuhan bagi populasi adalah pertambahan jumlah individu. Pertumbuhan itu merupakan proses biologis yang kompleks dimana banyak faktor yang dapat mempengaruhi. Faktor yang dapat mempengaruhi pertumbuhan digolongkan menjadi faktor dalam dan faktor luar, yang dapat dikontrol dan ada factor yang susah dikontrol. Faktor dalam umumnya adalah faktor yang sukar untuk dikontrol, diantaranya ialah faktor umur, sex, genetik, parasit dan penyakit. Sedangkan 
faktor luar yang utama ialah makan dan lingkungan atau kualitas perairan (Effendie, 2003 ; 2004).

Dalam bidang budidaya perikanan kualitas air memegang peranan penting karena seluruh siklus hidup biota yang dipelihara berada dalam air. Selain air harus jernih, bebas pencemaran, air yang dikhususkan untuk budidaya harus pula memperhatikan fisik dan kimia air tertentu. Sifat fisika dan kimia air untuk budidaya ikan air tawar yang harus diketahui yaitu suhu, pertukaran air, kedalaman, kekeruhan, kandungan oksigen terlarut, derajat keasaman air serta logam berat terutama Merkuri (Hg). Berdasarkan standar parameter kualitas air pada budi daya ikan air tawar dapat dilihat pada Tabel 1 .

Tabel 1. Parameter Kualitas Air Pada Budi Daya Ikan Air Tawar SNI $7550: 2009$

\begin{tabular}{lll}
\hline \multicolumn{1}{c}{ Jenis Parameter } & \multicolumn{1}{c}{ Satuan } & \multicolumn{1}{c}{ Kisaran } \\
\hline Suhu & ${ }^{0} \mathrm{C}$ & $25-32$ \\
\hline $\mathrm{pH}$ & - & $6.5-8.5$ \\
\hline Oksigen Terlarut & $\mathrm{mg} / \mathrm{l}$ & $\geq 3$ \\
\hline Amoniak & $\mathrm{mg} / \mathrm{l}$ & $<0.02$ \\
\hline Kecerahan & $\mathrm{Cm}$ & $30-40$ \\
\hline Cadmium & $\mathrm{ppm}$ & 0.01 \\
\hline Timbal & $\mathrm{ppm}$ & 0.03 \\
\hline Hg & $\mathrm{ppm}$ & 0.001 \\
\hline NH3 & $\mathrm{mg} / \mathrm{It}$ & $<0.016$ \\
\hline Kekeruan & $\mathrm{cm}$ & $40-50$ \\
\hline Karbondioksida & $\mathrm{mg} / \mathrm{It}$ & $<15$ \\
(CO2) & & \\
\hline Nitrit (NO2) & $\mathrm{ppm}$ & $<0.05$ \\
\hline Alkalinitas & $\mathrm{mg} / \mathrm{It}$ & $>20$ \\
\hline Kesadahan Total & $\mathrm{mg} / \mathrm{It}$ & $>20$ \\
\hline
\end{tabular}

Parameter kualitas air pada lokasi budidaya merupakan cerminan dari faktor fisik,kimia dan biologi perairan, dimana parameter tersebut harus dapat dikelola dengan baik,sehingga dapat mendukung terhadap pertumbuhan ikan (Boyd, 1982 ;1990). Data tentang kegiatan budidaya di Kecamatan Suwawa Tengah dapat dilihat pada Tabel 2:

Tabel 2. Kegiatan Budidaya Ikan Air Tawar Di Kecamatan Suwawa Tengah

\begin{tabular}{lcccc}
\hline \multicolumn{1}{c}{ Desa } & $\begin{array}{c}\text { Jumlah } \\
\text { RTP }\end{array}$ & $\begin{array}{c}\text { Luas } \\
\text { Kolam } \\
(\mathrm{Ha})\end{array}$ & $\begin{array}{c}\text { Sumber } \\
\text { Air }\end{array}$ & $\begin{array}{c}\text { Kegiatan } \\
\text { Budidaya }\end{array}$ \\
\hline Duano & 14 & 0.071 & Mata Air & Pembesaran \\
\hline Lompotoo & 24 & 0.400 & Mata Air & Pembesaran \\
\hline Tapadaa & 10 & 0.174 & Sungai & Pembesaran \\
\hline
\end{tabular}

(Dinas Kelautan dan Perikanan Kabupaten Bone Bolango)

Kecamatan Suwawa Tengah merupakan lokasi penambangan emas. Berdasarkan wawancara dengan masyarakat setempat bahwa proses penanganan limbah hasil akhir kegiatan penambangan belum baik. Terindikaksi hasil buangan limbahnya dapat mempengaruhi kondisi perairan setempat.

Berdasarkan hal tersebut diatas, maka perlu melakukan penelitian tentang "Analisis Kualitas Air Pada Lokasi Budidaya Ikan Air Tawar di Kecamatan Suwawa Tengah". Permasalahn pada penelitian ini adalah bagaimana kualitas air di lokasi budidaya ikan air tawar di Kecamatan Suwawa Tengah. Tujuan penelitian adalah: untuk mengetahui kualitas air di lokasi budidaya Ikan air tawar di Kecamatan Suwawa Tengah. Manfaat penelitian adalah tersedianya data kualitas air yakni parameter fisik dan kimia air pada lokasi budidaya Ikan air tawar di Kecamatan Suwawa Tengah.

\section{METODE PENELITIAN}

Metode yang digunakan dalam penelitian ini adalah metode observasi adalah melakukan pengamatan secara langsung terhadap subyeksubyek yang menjadi bagian dari permasalahan dan pengukuran parameter fisik dan kimia air di lokasi penelitian.

Lokasi pelaksanaan penelitian di Kecamatan Suwawa Tengah Kabupaten Bone Bolango (Gambar 1).

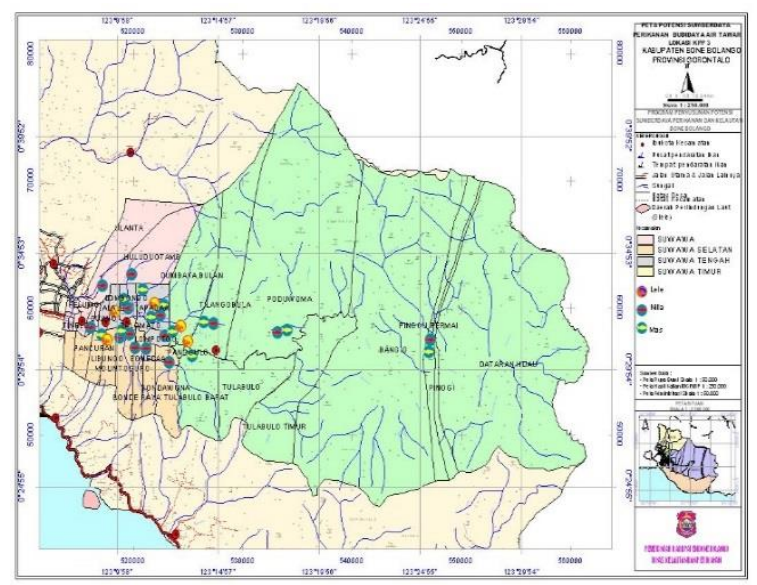

Gambar 1. Lokasi pelaksanaan penelitian di Kecamatan Suwawa Tengah Kabupaten Bone Bolango. (Dinas Kelautan dan Perikanan Kabupaten Bone Bolango 2012)

Pengukuran beberapa parameter kualitas air dilakukan secara insitu yakni pengukuran secara langsung di lapangan dan parameter lainnya dilakukan uji laboratorium. Parameter yang diukur langsung di lapangan (in situ) antara lain: suhu, $\mathrm{pH}$, kecerahan, suspensi terlarut dan oksigen terlarut. Untuk analisa logam berat di analisa menggunakan AAS di Laboratorium Pengujian dan Pengelolaan (LPPMHP) Mutu Hasil Perikanan.

Jenis data yang diambil dalam penelitian ini meliputi data primer dan data sekunder. Data primer terdiri dari parameter fisik (suhu, kecerahan, intensitas cahaya, padatan tersuspensi TSS) parameter kimia (Oksigen terlarut, $\mathrm{pH}$, Logam Berat (Merkuri, cadmium dan timbal). Sedangkan data 


\begin{tabular}{llll}
\hline Jenis Parameter & Satuan & Hasil Pengukuran \\
\hline Suhu & ${ }^{0} \mathrm{C}$ & 30 & \\
\hline $\mathrm{pH}$ & - & 8.1 & \\
\hline Oksigen Terlarut & $\mathrm{mg} / \mathrm{l}$ & 10 & \\
\hline Kecerahan & $\mathrm{cm}$ & 30 & \\
\hline Cadmium & $\mathrm{ppm}$ & 0.00004 & \\
\hline Timbal & $\mathrm{ppm}$ & 0.013 & \\
\hline $\mathrm{Hg}$ & $\mathrm{ppm}$ & 0.0050 & \\
sekunder adalah & data-data & pendukung & yang
\end{tabular}

menunjang hasil penelitian baik yang di dapat dari kajian literatur maupun bahan-bahan pendukung lainnya.

Analisis data pada penelitian ini menggunakan analisa deskriptif dan analisa kuantitatif. Analisa deskriptif yakni menjelaskan dan memaparkan hasil kegiatan sesuai dengan kaidah-kaidah ilimiah. analisa kuantitatif yaitu data ditampilkan melalui hasil pengukuran dan perhitungan.

\section{HASIL DAN PEMBAHASAN}

Kualitas air merupakan keadaan dan sifatsifat fisik, kimia dan biologi suatu perairan yang dibandingkan dengan standar kelayakan untuk persyaratan keperluan tertentu, misalnya kualitas air untuk perikanan, pertanian dan air minum, rumah sakit, industri dan lain sebagainya. Sehingga menjadikan persyaratan kualitas air berbeda-beda sesuai dengan peruntukannya (Ismoyo, 1994). Susanto (2004) menyatakan kualitas air untuk budidaya ikan air tawar harus memenuhi beberapa persyaratan karena air yang kurang baik akan menyebabkan ikan mudah terserang penyakit. Sumber air yang baik dalam pemeliharaan ikan harus memenuhi kriteria kulitas air yang meliputi sifat -sifat fisika dan sifat- sifat kimia seperti suhu, $\mathrm{pH}$, kekeruhan DO, dan sebagainya. Kualitas air usaha budidaya sangat menentukan tingkat keberhasilan. Tingginya atau rendahnya kualitas air akan berakibat fatal bagi pertumbuhan ikan.

Kualitas air yang di ukur dalam penelitian adalah suhu air, pH air dan Oksigen. Berdasarkan hasil pengukuran kualitas air selama penelitian di masing-masing desa di Kecamatan Suwawa Tengah dapat dilihat pada tabel berikut.

Table 3. Hasil Pengukuran Kualitas Air di Lokasi Penelitian Desa Duano

\begin{tabular}{lll}
\hline \multicolumn{1}{c}{ Jenis Parameter } & Satuan & Hasil Pengukuran \\
\hline Suhu & ${ }^{0} \mathrm{C}$ & 32.4 \\
\hline $\mathrm{pH}$ & - & 8.4 \\
\hline Oksigen Terlarut & $\mathrm{mg} / \mathrm{l}$ & 8 \\
\hline Kecerahan & $\mathrm{cm}$ & 40 \\
\hline Cadmium & $\mathrm{ppm}$ & 0.00039 \\
\hline Timbal & $\mathrm{ppm}$ & 0.021 \\
\hline $\mathrm{Hg}$ & $\mathrm{ppm}$ & 0.00076
\end{tabular}

Table 4. Hasil Pengukuran Kualitas Air di Lokasi Penelitian Desa Tapadaa

Table 5. Hasil Pengukuran Kualitas Air di Lokasi Penelitian Desa Lompotoo

\begin{tabular}{lll}
\hline \multicolumn{1}{c}{ Jenis Parameter } & Satuan & Hasil Pengukuran \\
\hline Suhu & ${ }^{0} \mathrm{C}$ & 30.5 \\
\hline $\mathrm{pH}$ & - & 8.5 \\
\hline Oksigen Terlarut & $\mathrm{mg} / \mathrm{l}$ & 8.4 \\
\hline Kecerahan & $\mathrm{cm}$ & 34 \\
\hline Cadmium & $\mathrm{ppm}$ & 0.00003 \\
\hline Timbal & $\mathrm{ppm}$ & 0.015 \\
\hline $\mathrm{Hg}$ & $\mathrm{ppm}$ & 0.0040 \\
\hline
\end{tabular}

Table 6. Hasil Pengukuran Kualitas Air di Lokasi Penelitian Daerah Aliran Sungai Bone

\begin{tabular}{lll}
\hline Jenis Parameter & Satuan & Hasil Pengukuran \\
\hline Suhu & ${ }^{0} \mathrm{C}$ & 32 \\
\hline $\mathrm{pH}$ & - & 8.4 \\
\hline Oksigen Terlarut & $\mathrm{mg} / \mathrm{l}$ & 6 \\
\hline Kecerahan & $\mathrm{cm}$ & 100 \\
\hline Cadmium & $\mathrm{ppm}$ & - \\
\hline Timbal & $\mathrm{ppm}$ & 0.092 \\
\hline $\mathrm{Hg}$ & $\mathrm{ppm}$ & 0.0056 \\
\hline
\end{tabular}

\subsection{Suhu}

Suhu air adalah faktor abiotik yang memegang peranan penting bagi kehidupan organisme perairan. Suhu air sangat dipengaruhi oleh jumlah sinar matahari yang jatuh ke permukaan air yang sebagian dipantulkan kembali ke atmosfer dan sebagian lagi diserap dalam bentuk energi panas. Pengukuran suhu sangat perlu untuk mengetahui karakteristik perairan.Penurunan biomassa dan keanekaragaman ikan menurun ketika suhu air meningkat lebih dari $28^{\circ} \mathrm{C}$ (Boyd, 1990).

Suhu atau temperatur merupakan salah satu faktor penentu kehidupan ikan. Hasil pengukuran suhu di lokasi penelitian yakni berkisar $30^{\circ} \mathrm{C}-$ $32.4^{0} \mathrm{C}$. Amri (2002 ; 2013) menyatakan bahwa kisaran suhu yang baik bagi kehidupan ikan antara $25-30^{\circ} \mathrm{C}$ sementara itu, jika suhu air berada dibawah $14^{\circ} \mathrm{C}$ ikan akan mengalami kematian. Jika suhu air turun hingga dibawah $25^{\circ} \mathrm{C}$ daya cerna ikan terhadap makanan yang dikonsumsi berkurang. Sebaliknya jika suhu naik hingga $30^{\circ} \mathrm{C}$ ikan akan stres karena kebutuhan oksigenya semakin tinggi.hal ini ditegaskan pula oleh Khairuman dan Subenda. (2002), bahwa suhu air yang normal untuk budidaya ikan berkisar antara $25-30^{\circ} \mathrm{C}$.

Suhu merupakan faktor fisik yang sangat penting di air, karena bersama-sama dengan zat/unsure yang terkandung didalamnya akan menentukan massa jenis air, dan bersama-sama dengan tekanan dapat digunakan untuk menentukan densitas air. Selanjutnya, densitas air dapat digunakan untuk menentukan kejenuhan air. Suhu air sangat bergantung pada tempat dimana air tersebut berada. Kenaikan suhu air di badan air, 
saluran air, sungai, danau dan lain sebagainya akan menimbulkan akibat sebagai berikut:

1) Jumlah oksigen terlarut di dalam air menurun;

2) Kecepatan reaksi kimia meningkat;

3) Kehidupan ikan dan hewan air lainnya terganggu.

Jika batas suhu yang mematikan terlampaui, maka akan menyebabkan ikan dan hewan air lainnya mati. Suhu dapat mempengaruhi fotosintesa di perairan baik secara langsung maupun tidak langsung. Pengaruh secara langsung yakni suhu berperan untuk mengontrol reaksi kimia enzimatik dalam proses fotosintesa. Tinggi suhu dapat menaikkan laju maksimum fotosintesa, sedangkan pengaruh secara tidak langsung yakni dalam merubah struktur hidrologi kolom perairan yang dapat mempengaruhi distribusi fitoplankton (Ghufran, dan Tancung, 2005). Suhu air memiliki peranan penting bagi organisme dalam melakukan metabolisme dan berkembangbiak

Pengaruh suhu secara tidak langsung dapat menentukan stratifikasi massa air, stratifikasi suhu di suatu perairan ditentukan oleh keadaan cuaca dan sifat setiap perairan seperti pergantian pemanasan dan pengadukan, pemasukan atau pengeluaran air, bentuk dan ukuran suatu perairan. Suhu air yang layak untuk budidaya ikan laut adalah $27-32{ }^{\circ} \mathrm{C}$ (Mayunar et al., 1995). Kenaikan suhu perairan juga menurunkan kelarutan oksigen dalam air, memberikan pengaruh langsung terhadap aktivitas ikan disamping akan menaikkan daya racun suatu polutan terhadap organisme perairan. Suhu air antara $35-40^{\circ} \mathrm{C}$ merupakan suhu kritis bagi kehidupan organisme yang dapat menyebabkan kematian (Junaidi, 2012).

Di Indonesia, suhu udara rata-rata pada siang hari di berbagai tempat berkisar antara $28,2^{\circ} \mathrm{C}$ sampai $34,6{ }^{\circ} \mathrm{C}$ dan pada malam hari suhu berkisar antara $12,8^{\circ} \mathrm{C}$ sampai $30^{\circ} \mathrm{C}$. Keadaan suhu tersebut tergantung pada ketinggian tempat dari atas permukaan laut. Suhu air umumnya beberapa derajat lebih rendah dibanding suhu udara disekitarnya. Secara umum, suhu air di perairan Indonesia sangat mendukung bagi pengembangan budidaya perikanan (Cholik 2005).

Berdasarkan hasil penelitian maka kondisi suhu air masih dalam batasan normal.

\subsection{Derajat Keasaman (pH)}

Nilai $\mathrm{pH}$ didefinisikan sebagai negatif logaritma dari konsentrasi ion Hodrogen dan nilai asam ditunjukkan dengan nilai $1 \mathrm{~s} / \mathrm{d} 7$ dan basa $7 \mathrm{~s} / \mathrm{d}$ 14. Kebanyakan perairan umum mempunyai nilai pH antara 6-9. Perairan yang asam lebih kecil dan dapat menurun sampai 2. Batas toleransi organisme perairan terhadap $\mathrm{pH}$ bervariasi dan dipengaruhi antara lain suhu, oksigen terlarut, alkalinitas, kandungan kation dan anion maupun jenis dan tempat hidup organisme. Menurut Subagja (2009) perairan yang ideal bagi kegiatan budidaya perikalnan adalah $6,8 \mathrm{~s} / \mathrm{d}$ 8,5 dan perairan dengan $\mathrm{pH}<6$ menyebabkan organisme renik tidak dapat hidup dengan baik.

Derajat keasaman disebut juga dengan $\mathrm{pH}$, nilai $\mathrm{pH}$ normal ikan-ikan nila adalah $6-9$ (Mudjiman dan Suyanto , 2003). Nilai pH diatas 10 dapat membunuh ikan, sementara nilai $\mathrm{pH}$ dibawah 5 mengakibatkan pertumbuhan ikan terhambat. Hal ini ditegaskan oleh Amri dan Khairuman (2013), bahwa $\mathrm{pH}$ optimal untuk pertumbuhan ikan adalah $6-8$. $\mathrm{pH}$ air hasil pengukuran lokasi penelitian berkisar $8,1-8.5$. Hal ini menunjukan bahwa $\mathrm{pH}$ air selama penelitian stabil dan sesuai untuk budidaya ikan. Sebagian besar biota akuatik sensitif terhadap perubahan $\mathrm{pH}$ dan menyukai nilai $\mathrm{pH}$ sekitar 7-8.5. Nilai pH sangat mempengaruhi proses biokimiawi perairan, misalnya proses nitrifikasi akan berakhir jika $\mathrm{pH}$ rendah. Selain itu toksisitas logam-logam memperlihatkan peningkatan pada $\mathrm{pH}$ rendah (Effendi, 2004).

Derajat keasaman $(\mathrm{pH})$ dipengaruhi oleh konsentrasi karbondioksida serta ion-ion bersifat asam atau basa. Fitoplankton dan tanaman air akan mengambil karbondioksida selama proses fotosintesis berlangsung, sehingga mengakibatkan $\mathrm{pH}$ perairan menjadi meningkat pada siang hari dan menurun pada malam hari.

\subsection{Kecerahan}

Kecerahan sangat penting karena erat kaitannya dengan proses fermentasi yang terjadi di perairan. Kecerahan perairan dapat diukur dengan alat yang dinamakan Keping Secchi. Effendi (2000) menyatakan bahwa kecerahan $<3 \mathrm{~m}$ adalah tipe peraran yang subur (eutropik), antara 3-6 m kesuburan sedang (mesotrofik) dan > $6 \mathrm{~m}$ digolongkan pada tipe perairan kurang subur (oligotrofik).

Tingkat kecerahan dan kekeruhan air sangat berpengaruh terhadap pertumbuhan patin Zat atau material terlarut (tersuspensi) seperti lumpur, senyawa, dan anorganik, plankton dan mikroorganisme diduga kuat sebagai penyebab kekeruhan air. Kekeruhan air menyebabkan sinar yang sampai ke air lebih banyak dihamburkan dan diserap daripada ditransmisikan disekelilingnya, pengukuran kekeruhan air sering dilakukan dengan melihat tingkat kecerahan air. Untuk mengukur kecerahan air digunakan alat yang disebut sechi disc ( keeping sechi) (Subagja,2009). Tingkat kecerahan air pada lokasi penelitian yakni $30-40 \mathrm{~cm}$. Pada lokasi Sungai Bone kecerahan sampai $100 \%$. Hal ini baik dan layak untuk kehidupan ikan-ikan air tawar yang biasa dibudidayakan yakni ikan nila, patin dan lele.

Selain dipengaruhi oleh intensitas cahaya matahari yang masuk ke perairan, tingkat kecerahan 
juga dipengaruhi oleh perbedaan waktu pengukuran kecerahan, keadaan cuaca dan juga ketelitian dari orang yang melakukan pengukuran.

\subsection{Oksigen Terlarut (Dissolved Oxygen)}

Oksigen terlarut merupakan faktor pembatas bagi kehidupan organisme. Perubahan konsentrasi oksigen terlarut dapat menimbulkan efek langsung yang berakibat pada kematian organisme perairan. Sedangkan pengaruh yang tidak langsung adalah meningkatkan toksisitas bahan pencemar yang pada akhirnya dapat membahayakan organisme itu sendiri. Hal ini disebabkan oksigen terlarut digunakan untuk proses metabolisme dalam tubuh dan berkembang biak.

Oksigen terlarut merupakan kebutuhan dasar untuk kehidupan makhluk hidup didalam air maupun hewan teristrial. Penyebab utama berkurangnya oksigen terlarut di dalam air adalah adanya bahan-bahan buangan organik yang banyak mengkonsumsi oksigen sewaktu penguraian.

Konsentrasi oksigen terlarut yang aman bagi kehidupan diperairan sebaiknya harus diatas titik kritis dan tidak terdapat bahan lain yang bersifat racun, konsentrasi oksigen minimum sebesar $2 \mathrm{mg} / \mathrm{l}$ cukup memadai untuk menunjang secara normal komunitas akuatik di periaran (Boyd, 1990). budidaya adalah $5-8 \mathrm{mg} / \mathrm{l}$ (Effendi, 2000).

Kandungan oksigen terlarut di lokasi penelitian adalah $6-10 \mathrm{mg} / \mathrm{l}$. Kandungan oksigen terlarut ini layak untuk kehidupan ikan-ikan air tawar seperti ikan nila, patin dan lele yang dibudidayakan di lokasi kolam yang diteliti.

\subsection{Logam Berat}

Logam berat harus diwaspadai keberadaannya di perairan karena merupakan salah satu unsur pencemar perairan yang berbahaya. Logam berat susah dihancurkan (non degradable), terakumulasi ke lingkungan, terutama mengendap di dasar perairan membentuk senyawa kompleks bersama bahan organik dan anorganik secara adsorbsi sehingga menjadi penyebab utama logam berat menjadi bahan pencemar berbahaya oleh organisme hidup di lingkungan perairan (Heryando, 2004)).

Logam berat seperti merkuri, timbal, cadmium merupakan bahan pencemar yang cukup mengkhawatirkan pada lokasi penelitian yakni kecamatan Suawwa Tengah karena daerah tersebut dilakukan PETI (penambangan tanpa izin) emas.

Logam berat pada perairan susah mengalami degradasi, akan diabsorpsi dalam tubuh organisme sehingga logam berat seperti $\mathrm{Pb}$ dan $\mathrm{Cd}$ ini termasuk golongan logam berat yang berbahaya dan dapat masuk ke dalam tubuh melalui saluran pernafasan dan pencernaan (Darmono, 2001).

Logam berat timbal dan cadmium dapat menyebabkan keracunan yang akut dan kronis.
Keracunan akut logam timbal ditandai oleh rasa terbakarnya mulut, terjadinya perangsangan dalam gastrointestinal dengan disertai diare dan gejala keracunan kronis ditandai dengan rasa mual, anemia, sakit di sekitar perut dan dapat menyebabkan kelumpuhan (Darmono, 2001). Bahaya kronis dari keracunan logam cadmium, biasanya mengakibatkan kerusakan ginjal, kerusakan sistem syaraf dan kerusakan pada sebagian renal tubules. Penyerapan cadmium dalam tubuh akan terkonsentrasi di dalam hati dan ginjal.

Adanya kandungan logam berat pada perairan dapat membahayakan ikan dan organisme lainnya yang hidup di perairan. Ikan termasuk organisme nekton, dapat bergerak aktif dengan cepat sehingga mempunyai kemampuan menghindarkan diri dari pengaruh pencemaran air. Namun demikian, pada ikan yang hidup dalam habitat yang terbatas (seperti sungai, danau, dan teluk), sulit menghindari diri dari pengaruh pencemaran tersebut. Akibatnya, unsur-unsur pencemaran seperti logam berat akan masuk ke dalam tubuh ikan dan akan terakumulasi (Agustina, 2011).

Kandungan logam berat yang tinggi pada perairan menyebabkan kontaminasi, akumulasi bahkan pencemaran terhadap lingkungan seperti biota, sedimen, air dan sebagainya (Heryando, 2004). Logam berat dapat dibedakan atas dua golongan berdasarkan kegunaannya, yaitu (Hutagalung, 1991):

1. Logam berat pada konsentrasi tertentu berfungsi sebagai mikronutrien yang bermanfaat bagi kehidupan organisme perairan, seperti $\mathrm{Zn}, \mathrm{Fe}, \mathrm{Cu}, \mathrm{Co}$.

2. Logam berat yang belum diketahui kegunaannya bagi organisme perairan, seperti $\mathrm{Hg}, \mathrm{Cd}$, dan $\mathrm{Pb}$.

Heryando (2004) menjelaskan senyawa logam berat banyak digunakan untuk kegiatan industri sebagai bahan baku, katalisator, biosida maupun sebagai additive. Limbah yang mengandung logam berat ini akan terbawa oleh sungai dan karenanya limbah industri merupakan sumber pencemar logam berat yang potensial bagi pencemaran laut.

Dalam perairan, logam-logam ditemukan dalam bentuk (Heryando, 2004):

1. Terlarut, yaitu ion logam bebas air dan logam yang membentuk kompleks dengan senyawa organik dan anorganik.

2. Tidak terlarut, terdiri dari partikel yang berbentuk koloid dan senyawa kompleks metal yang terabsorbsi pada zat tersuspensi.

\subsubsection{Merkuri}

Merkuri atau yang biasa disebut air raksa) dan disingkat $\mathrm{Hg}$ adalah salah satu jenis logam yang banyak ditemukan di alam dan tersebar dalam batu - batuan, biji tambang, tanah, air dan udara sebagai 
senyawa anorganik dan organik. Selain itu, berbagai jenis aktivitas manusia dapat meningkatkan kadar ini. Toksisitas merkuri berbeda sesuai bentuk kimianya, misalnya merkuri inorganik bersifat toksik pada ginjal, sedangkan merkuri organik seperti metil merkuri bersifat toksis pada sistim syaraf pusat. Dikenal 3 bentuk merkuri, yaitu:

1. Merkuri elemental $(\mathrm{Hg})$ : terdapat dalam gelas termometer, tensimeter air raksa, amalgam gigi, alat elektrik, batu batere dan cat

2. Merkuri inorganik: dalam bentuk $\mathrm{Hg}++$ (Mercuric) dan $\mathrm{Hg}+$ (Mercurous)

3. Merkuri organic.

Hasil pengukuran logam berat yakni merkuri ( $\mathrm{Hg})$ di lokasi budidaya dan sungai Bone termasuk lokasi pengambilan data berkisar 0,00076 ppm 0,0056. Kisaran ini masih berada dibawah ambang batas aman untuk kegiatan budidaya

\subsubsection{Timbal $(\mathbf{P b})$}

Timbal biasa dikenal dengan nama timah hitam, dalam bahasa ilmiah dinamakan plumbum sehingga disimbolkan dengan $\mathrm{Pb}$. Nomor atom timbal adalah (NA) 82 dan berat atom (BA) 207.2 (Palar, 2008). Timbal (Pb) merupakan jenis logam lunak berwarna coklat kehitaman dan mudah dimurnikan. Logam Pb lebih tersebar luas dibanding kebanyakan logam toksik lainnya dan secara alamiah terdapat pada batu-batuan serta lapisan kerak bumi.

Timbal banyak digunakan pada industri sebagai zat tambahan bahan bakar, pigmen timbal dalam cat yang merupakan penyebab utama peningkatan kadar $\mathrm{Pb}$ di lingkungan (Agustina, 2011).

Hasil pengukuran Timbal $(\mathrm{Pb})$ pada lokasi penelitian masih berada dibawah ambang batas aman untuk kegiatan budidaya yakni 0,021 ppm 0,092 ppm.

\subsubsection{Kadmium (Cd)}

Kadmium di alam sangat berkaitan dengan keberadaan logam $\mathrm{Pb}$ dan $\mathrm{Zn}$. Palar (2008) menyatakan pada industri pertambangan $\mathrm{Pb}$ dan $\mathrm{Zn}$, proses pemurniannya akan selalu memperoleh hasil samping kadmium yang terbuang dalam lingkungan. Logam kadmium mempunyai berat atom 112.41; titik cair $321{ }^{\circ} \mathrm{C}$ dan massa jenis $8.65 \mathrm{gr} / \mathrm{ml}$ (Heryando, 2004). Kadmium biasanya digunakan sebagai pigmen dalam pembuatan keramik, penyepuhan listrik, pembuatan aloi dan baterai alkali.

Hasil pengukuran logam berat Kadmium (Cd) pada daerah lokasi penelitian 0,00003 ppm 0,00039 ppm Cd . Kisaran tersebut masih berada dibawah ambang batas aman untuk kegiatan budidaya.

\section{KESIMPULAN DAN SARAN}

Hasil pengukuran parameter kualitas air di lokasi budidaya ikan air tawar Kecamatan Suwawa Tengah yakni Desa Tapadaa, Desa Lompotoo, Desa Duano dan aliran Sungai Bone masih layak untuk kegiatan budidaya ikan air tawar. Nilai parameter fisik dan kimia air hasil pengukuran adalah suhu $30^{\circ} \mathrm{C}-32.4^{\circ} \mathrm{C}$, pH Derajat keasaman 8.1 - 8.5. Oksigen terlarut (DO) $6-10 \mathrm{mg} / \mathrm{L}$, tingkat kecerahan air $30-40 \mathrm{~cm}$, dan intensitas cahaya $90 \%$. Hasil pengukuran logam berat yakni merkuri $(\mathrm{Hg})$ 0.00076 ppm - 0.0056, Kadmium (Cd) 0.00003 ppm -0.00039 ppm sedangkan Timbal $(\mathrm{Pb})$ yakni 0.021 ppm -0.092 ppm. Konsentrasi logam berat $\mathrm{Hg}, \mathrm{Cd}$ dan $\mathrm{Pb}$ masih dibawah ambang batas aman untuk kegiatan budidaya.

\section{DAFTAR PUSTAKA}

Agustina, N. (2011). Bioakumulasi Logam Berat Pb dan Cd dalam daging dan Insang Ikan Nila di Danau Cikaro. Skripsi Fakultas Perikanan dan Ilmu Kelautan UNPAD, Jatinangor

Amri, K dan Khairuman. (2002). Buku Pintar Budidaya Ikan Konsumsi. Jakarta: Agromedia

Amri, K dan Khairuman. (2013). Budi Daya Ikan. Jakarta: Agromedia

Boyd. C.E. (1990). Water Quality Management For Pond Fis Culture. Department Of Fisheries and Allied Aquaculture. Aurburn University Alabama. Agricultural Experiment Station. 318 page.

Boyd, C. E. (1982). Water Quality Management for Pond Fish Culture Development in Aquaculture and Fish Science, Vol. 9. Elsevier Scintific Pub. Comp.

Cholik. (2005). Akuakultur. Masyarakat Perikanan Nusantara. Taman Akuarium Air Tawar. Jakarta.

Darmono. (2001). Lingkungan Hidup dan Pencemaran: Hubungannya Dengan Toksikologi Senyawa Logam. Jakarta: UI Press. Hal. 28 - 29.

Effendie. (2003). Biologi Perikanan. Penerbit Yayasan Pustaka Nusantara. Yogyakarta.

Effendie, M. I. (2004). Metoda Biologi Perikanan, Cetakan II, Yayasan Dewi Sri. Bogor.

Effendie. M. I. (2004). Pengantar Akuakultur. Penebar Swadaya. Jakarta.

Effendi. (2000). Telaahan Kualitas Air, bagi Pengelolaan Sumberdaya dan Lingkungan Perairan. Jurusan manajemen Sumberdaya Perairan. Fakultas Perikanan dan Kelautan, IPB. Bogor 
Ghufran, K H M dan Tancung, B A. (2005). Pengelolaan Kualitas Air dalam Budidaya Perairan. Rineka Cipta. Jakarta.

Hardjojo B dan Djokosetiyanto. (2005). Pengukuran dan Analisis Kualitas Air. Edisi Kesatu, Modul 1 - 6. Universitas Terbuka. Jakarta

Ismoyo IH. (1994). Kamus Istilah Lingkungan. Jakarta: PT. Bina Rena Pariwara.

Junaidi M. Affan. (). Cages Based On Environmental And Water Quality Factors In East Coast Bangka Tengah District. Depik, 1(1):78-85. April 2012. ISSN 2089-7790

Khairuman dan Subenda. (2002). Budidaya Ikan Air Tawar: Ikan Bandeng, Ikan Nila, Ikan Lele. Cetakan Kelima . 113 p. Yogyakarta : Kanisius

Kordi, K. M. (). Panduan Lengkap Memelihara Ikan Air Tawar Di Kolam Terpal. Yogyakarta. Penerbit Lily Publisher. 280 hal.

Mayunar, R. Purba, P.T. Imanto. (1995). Pemilihan lokasi budidaya ikan laut. Prosiding temu usaha pemasyarakatan teknologi keramba jaring apung bagi budidaya laut, Puslitbang Perikanan. Badan Litbang Pertanian: 179 189.

Mujiman, A, dan Suyanto, R. (2003). Budidaya Udang Windu. Penebar Swadaya. Jakarta. 211 hal

Palar H. (2008). Pencemaran dan Toksikologi Logam Berat. Jakarta: Rineka Cipta

Susanto. (2004). Budidaya Mas. Jakarta: Kanisius

Subagja. (2009). Bioindikator Kualitas Air. Universitas Trisakti. Jakarta.

SNI 7550. (2009). Produksi Ikan Nila (Oreochromis nilotica) Kelas Pembesaran di Kolam Air Tenang. Badan Standardisasi Nasional

Tjarmana, Maman., (1999). Sistem Budi Daya Ikan. Universitas Terbuka, Jakarta. 